\title{
FEMTOSECOND DIRECT LASER WRITING OF PHOTONIC SPATIAL FILTERS IN SODA-LIME GLASS
}

\author{
D. Gailevičius ${ }^{a}$, V. Purlys ${ }^{a}$, L. Maigyte ${ }^{b}$, E. Gaižauskas ${ }^{a}$, M. Peckus ${ }^{a}$, R. Gadonas ${ }^{a}$, \\ and K. Staliūnas ${ }^{\mathrm{b}, \mathrm{c}}$ \\ ${ }^{a}$ Laser Research Center, Department of Quantum Electronics, Vilnius University, \\ Sauletekio 10, LT-10223 Vilnius, Lithuania \\ ${ }^{\mathrm{b}}$ Departament de Fisica i Enginyeria Nuclear, Universitat Politecnica de Catalunya, Spain \\ 'Institucio Catalana de Recerca i Estudis Avancats (ICREA) \\ E-mail: darius.gailevicius@ff.vu.lt
}

Received 22 May 2015; revised 23 August 2015; accepted 29 September 2015

\begin{abstract}
An experimental study of the efficiency of recently predicted photonic crystal $(\mathrm{PhC})$ based spatial filtering is provided. Photonic structures are fabricated using a direct laser writing technique employing point-by-point modification by tightly focused femtosecond pulses in soda-lime glass. Such PhCs are characterized by using an s-coefficient - a parameter defining PhC filter efficiency. We explore the dependences of filtering efficiency on different laser writing conditions, such as irradiation peak intensity and the polarization of laser beam. In addition, we show that the PhCs can also exhibit even asymmetric shapes of voxels under particular conditions.
\end{abstract}

Keywords: photonic crystal, spatial filtering, femtosecond fabrication, glass

PACS: 42.60.-v, 42.79.Ci, 81.16.-c, 81.05.-t

\section{Introduction}

Spatial (or angular) filtering is frequently used to improve the spatial quality of light beams by removing the undesired angular or far-field components of the radiation. A conventional design for spatial filtering comprises a confocal system of lenses with a diaphragm of appropriate diameter positioned in the confocal plane, blocking the undesired angular components of the spatial spectrum [1]. Such a configuration extends over at least two focal lengths of both lenses and is of a relatively large size - it could hardly be used in micro- or nano-scale photonic devices. Other, more sophisticated arrangements for spatial filtering based on liquid-crystal cells [2], utilization of thin film interfaces [3], anisotropic media [4], metallic grids [5], possibly including monolithically integrated passive beam shaping elements [6], etc. have not resulted in widespread technological applications. Recently, an alternative approach to spatial filtering has been suggested, which is based on propagation of light beams through photonic crystals (PhCs) - materials with a periodic modulation of the refractive index on a wavelength scale [7-10]. PhC based spatial filters are potentially advantageous due to their relatively small size as compared to the conventional spatial filters, that could enable the integration of such filters into microoptical devices or micro-laser resonators.

The well-known property of PhCs is the appearance of photonic band gaps, i. e. forbidden frequency ranges at which light waves cannot propagate [11]. Thus, the $\mathrm{PhCs}$ can provide frequency (chromatic) filtering, eliminating (reflecting) specific frequency components from the incident radiation. Similar to the chromatic band gaps, angular band gaps can also appear in PhCs, which can be engineered in such a way that for a given frequency only on- and around-axis waves are allowed to propagate. Angular filtering has been shown in twoand three-dimensional (2D and 3D) PhCs in the microwave and infrared regime $[7-10]$. The most simple mechanisms of spatial filtering by PhCs are based on angular band gaps, which appear if a condition related to a longitudinal modulation period, $d_{\|}<\lambda$, is met. However, despite the enormous progress in micro- and nanostructure fabrication technologies, the latter condition is still difficult to fulfill in the visible and near-infrared ranges. Perhaps, this is the reason why the spatial filtering by angular band gaps has never been experimentally 
demonstrated in optics. We note the recent demonstration of spatial filtering in acoustics by the so-called sonic crystals [12, 13], where the fabrication of structures on a millimeter scale is less challenging.

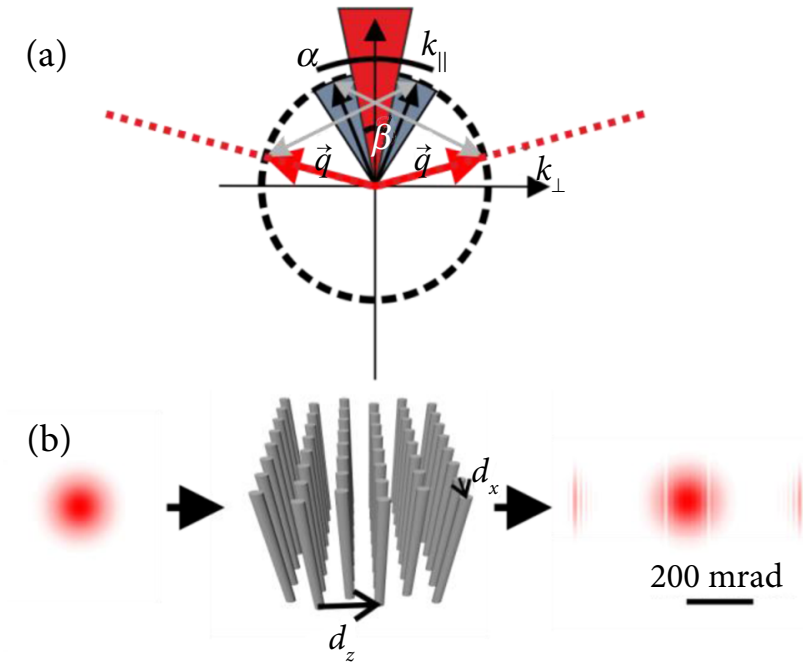

Fig. 1. Illustration of spatial filtering in a 2D PhC: (a) is the mechanism of resonant wave scattering in a gapless configuration, (b) is the schematic of the experimental arrangement. Filtering occurs when the waves in the dark triangle zones get into the resonant scattering condition with modulation wave vectors $\vec{q}=\left(q_{x}, q_{z}\right)$. Dashed lines show the direction of filtered out angular components. The spatial spectrum (far field) of the initial beam, consisting of the central (regular) part, and of the wings (the part to be removed), is shown by red and grey triangles.

As an alternative to the spatial filtering based on the angular band gaps, a mechanism of $\mathrm{PhC}$ based spatial filtering was proposed with the PhCs arranged in a gapless configuration [14]. In the latter case, a deflection of the angular components of radiation in the forward direction is observed (see Fig. 1(a)). The gapless spatial filtering can be obtained for substantially larger longitudinal periods of modulation $d_{\|}>\lambda$ (we will use $d_{z}$ to denote the thickness of one layer, two layers comprise one period $d_{\|}=2 d_{\mathrm{z}}$ ); hence, current fabrication techniques can be applied more easily. Such kind of filtering has been recently demonstrated experimentally in different 3D configurations using PhCs with a square symmetry in transverse space [15, 16, as well as photonic structures with axisymmetric rings [17, 18]. The gapless filtering has been recently proposed also to clean atomic ensembles on Bose-Einstein condensates [19].

Another advantage of the proposed spatial filtering alternative is the required relatively low refractive index modulation (of the order of $10^{-2}$ ), that is around two orders lower compared to $7-10]$. Such a low in- dex modulation suggests the possibility of inscription of such PhCs into the bulk of transparent materials, such as glass, by using femtosecond direct laser write techniques. Glass is an excellent alternative to other media, such as photoresists used in 3D laser lithography, that are more prone to issues with shrinkage, noise sensitivity and also destructive optical breakdown [20, 21]. However, this technique typically allows refractive index modulation, that is on the lower side $\left(\approx 10^{-3}\right)$ of the required index modulation, therefore a careful choice of processing parameters must be made in order to maximize it.

Due to the fact that relatively small transversal periods (of the order of 1 and $2 \mu \mathrm{m}$ for $2 \mathrm{D}$ and 3D axisymmetric PhCs, respectively) were used in the multilayer structures, formation of successive layers can modify the previous one and induce tension in the area of further successive layer fabrication. This makes it difficult to characterize such structures using conventional methods, such as phase contrast microscopy. The solution uses a characterization method based on the socalled $s$-coefficient, that is a phenomenological constant and allows the characterization of periodic structures without knowing its specific details (such as the amplitude $\Delta n_{\max }$ of refractive index modulation, the profile of refractive index change, the size of the modified regions or, more particularly, the longitudinal size of the modifications $\Delta l$ ). The $s$-coefficient can be interpreted as the scattering coefficient of one crystalline longitudinal period of the structure and expressed by (see Appendix $\mathrm{A}$ and $\mathrm{B}$ for detailed derivation)

$$
s=\pi^{3 / 2} \Delta n_{\max } \Delta l / \lambda_{0},
$$

and as it was shown in [16], can be used as a tool for determining the most appropriate crystal geometry for available laser processing parameters for a given application. For example, if we consider that for a given set of $\mathrm{PhC}$ fabrication we know the value of $s$, and a particular application requires $100 \%$ intensity depletion along a predefined filtering angle $\alpha$ for an arbitrary input beam, then to determine the number of $\mathrm{PhC}$ periods $N$ needed to achieve the best result we can use the condition $s \cdot N \approx 1.5$ (see Fig. 2). In addition, an approximate line width could be determined, which follows the relation $w \approx 50 \sqrt{s}$ mrad. Similarly, controlling $s$ might also be beneficial for other applications, e. $g$. axisymmetric super-collimation [22] or flat lensing [23]. A more complete overview of progress made in the field of PhC filters can be found in [24].

Although the $s$-coefficient has been found to be useful in determining the behaviour of the $\mathrm{PhC}$ filter, it should be stressed that the dependence of $s$ on any of processing parameters, such as DLW speed, peak 


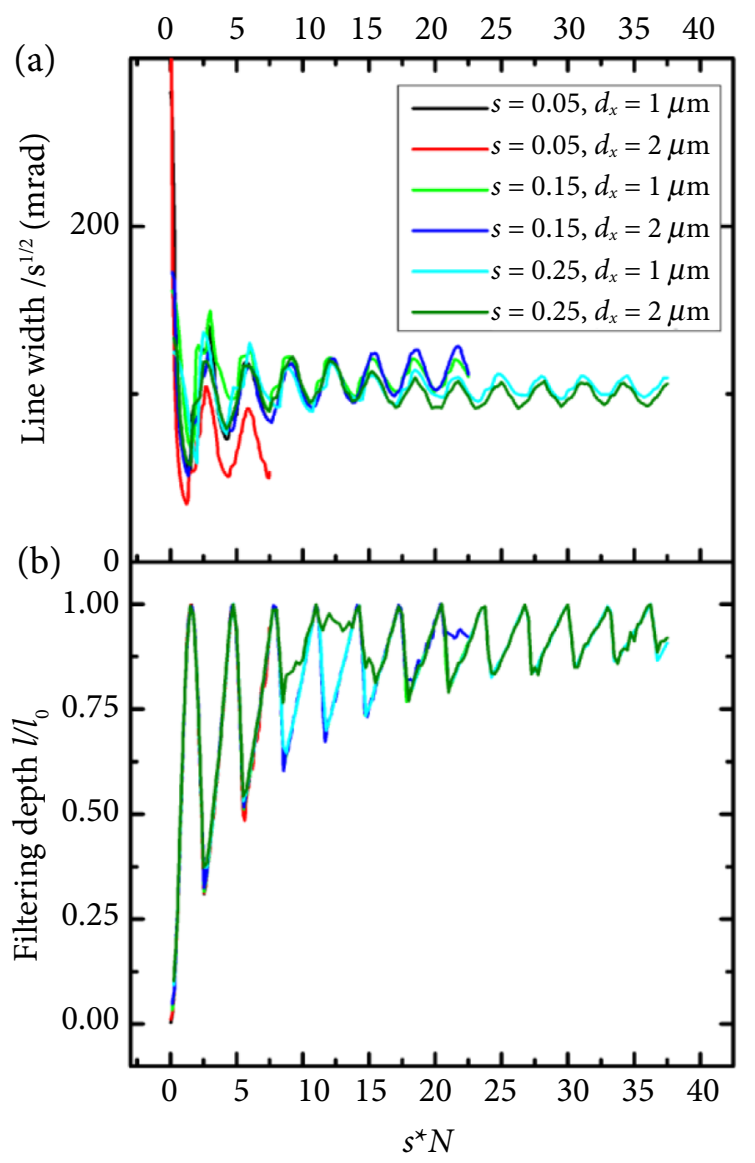

Fig. 2. (a) is the numerically calculated width and (b) is the depth of the angular filtering range, depending on the length of the structure for three different $s$-coefficient values: $0.05,0.15$, and 0.25 (for details on the numeric computation procedure see Appendix C).

intensity, pulse repetition rate, etc., has never been explored before. Little is known about optimization of $\mathrm{PhC}$ based filter fabrication conditions, in general. Therefore, this article is devoted to the experimental study of the PhC spatial filter efficiency depending on DLW conditions, or, in other words, the behaviours of the $s$-coefficient.

\section{Materials and methods}

The photonic structures were fabricated using a direct laser writing (DLW) technique employing pointby-point volumetric modification by tightly focused IR ( $\lambda=1030 \mathrm{~nm}$ from a Yb:KGW laser) femtosecond laser pulses $(\mathrm{FWHW} / 1.41=300 \mathrm{fs})$ in standard microscope soda-lime glass slides (Carl Roth, ISO $8037-1, n_{\text {ref }}=1.52$ ). This method is widely used for the inscription of various micro-optical and photonic components in glass, such as waveguides 25, 26, Bragg gratings [27], as well as vortex generators [28].
The geometry of fabricated PhCs is schematically depicted in Fig. 1(b). It is the simplest case, that allows only one-directional filtering. The geometry consists of parallel equidistant layers that are arranged to be perpendicular (in the longitudinal direction) to the optical axis of an incident beam. Each layer contains a one-dimensional periodic arrangement of parallel linear modified regions. The transverse period (lateral distance between modifications) was chosen to be $d_{x}=1 \mu \mathrm{m}$ for the analysis of irradiation conditions. Every second layer is transversally shifted by half of the transverse period with respect to the previous layer. This results in $N$ longitudinal periods, each having two layers. The length of longitudinal periods was selected to be $2 d_{z}=6 \mu \mathrm{m}$.

During formation of PhCs focusing was achieved by using a Zeiss $63 \times 1.4 \mathrm{NA}$ objective. PhC length was limited by the maximal working distance of the objective, i. e. $\approx 300 \mu \mathrm{m}$, that for the given geometry corresponds to the highest possible number of periods of $N=50$. A lower NA $<1$ objective lens, as used in [16, 19], might be more suitable for generating higher length modifications $\Delta l$ with a potentially higher amplitude of the refractive index modulation $\Delta n_{\text {max }}$, but results in spherical aberrations. Also, large period number PhCs are difficult to realize as mechanical stress accumulated throughout the structure can induce failures, leading to crack formation or even shattering. The process is similar to that which is used for cleaving brittle materials [30].

The fabrication algorithm and the fabrication setup are reported in detail in 15. PhCs were inscribed layer by layer by relative translation of the focal point inside the bulk of the glass sample. The translation speed was limited to $v_{\max }=5 \mathrm{~mm} / \mathrm{s}$, beyond which error free fabrication was not possible. We varied the pulse frequency $f$ and pulse energy $E$ during the first experiment phase, whereby $E$ was established by measuring the average beam power before the objective and by taking into account the total transmittance of the objective. The number of pulses per unit length (PPUL) was fixed at $20 \mu \mathrm{m}^{-1}$, which allows us to compare our results to those achieved in 16 . $f$ was selected to be 25 , 50,100 and $200 \mathrm{kHz}$. E values were set in the range of $0.01 \mu \mathrm{J}$ to $0.3 \mu \mathrm{J}$. We calculated the peak intensity (irradiance) values as in [29], with an approximate beam waist radius $\sim 300 \mathrm{~nm}$.

For every discrete combination of such parameters we formed $100 \times 100 \mu \mathrm{m}^{2}$ transversal size crystals having a different number of periods $N$. It should be noted that if the $s$-coefficient is below the approximate value of $s<0.025$, in order to achieve the condition of full filtering dips defined by the relation $s \cdot N \approx 1.5$, a large number of longitudinal periods $N>60$ is required, 
whereby for samples of $f=200 \mathrm{kHz}$ this condition was not met due to low filtering performance. Structures having a large number of periods, fabricated using high values of $E$ and $I$, succumbed to cracking, which was expected due to the fact that soda-lime glass is prone to thermal shock and has a higher expansion rate than optical grade glasses such as fused silica. Therefore, results for some low $s$-coefficient structures have not been analyzed. Furthermore, producing a sufficient number of samples is difficult due to the allowed processing speeds. This can be illustrated by taking into account time needed to produce an array of PhCs for $f=25 \mathrm{kHz}$, with at least 12 values of $E$, and $N=3,4$, $5 \ldots 50$. Such an array takes at least $\sim 3$ days to produce, whereby for $f=1 \mathrm{kHz}$ it would take at least 71 days, therefore an experimental part of this article dealing with the relation of $s$ to $E$ (including $I$ ) and $f$ has been limited to only a few frequency values acceptable for the level of the scope and scale of this study.

An interesting effect that we observed was the scattering efficiency asymmetric behaviour, that is discussed in further section. To minimize the dependence on multiple variables we employed a new single directional raster scan pattern in the DLW process of each individual layer of the PhCs. We selected 4 fixed angles of the linear polarization plane (electric field vector $\mathbf{E}$ ). The plain was fixed to be parallel to the $z$ axis and at $\gamma=0^{\circ}$ parallel to the $x$ axis. Other positions $\gamma=45$, $90,135^{\circ}$ are defined counter-clockwise to the positive $z$ axis. The PhCs (and line structures) used for asymmetry observation were written using the fabrication parameter values: $f=2 \mathrm{kHz}, E=65 \mathrm{~nJ}\left(I=56 \mathrm{TW} / \mathrm{cm}^{2}\right)$, $\nu=500 \mu \mathrm{m} / \mathrm{s}$ (PPUL $\left.4 \mu \mathrm{m}^{-1}\right), N=20$, where a lower frequency and PPUL value were chosen to reduce thermal accumulation effects while maintaining a reasonable processing speed.

Characterization of the fabricated PhCs was carried out by illuminating the samples with a continuous $633 \mathrm{~nm}$ wavelength He-Ne laser beam focused into $\mathrm{PhC}$ samples with a $10 \times 0.25 \mathrm{NA}$ objective (see Fig. 3(b)). Focusing provided a large angular range of the radiation illuminating the $\mathrm{PhC}$. To register the output, a CCD camera was placed $11 \mathrm{~mm}$ behind the sample in a fixed position. Only the central beam part of the radiation was recorded.

By measuring the angular intensity profile at the output of the PhC, we determined which components are filtered out. The $s$-coefficient was determined by calibrating numerical simulation data (derived by solving the paraxial propagation equation with a scattering matrix algorithm as in [15, 16, 24], and also by using the split-step procedure as described in Appendix $C$, whereby both gave equivalent results) with spatial intensity spectra behind $\mathrm{PhCs}$ of varying $N$.
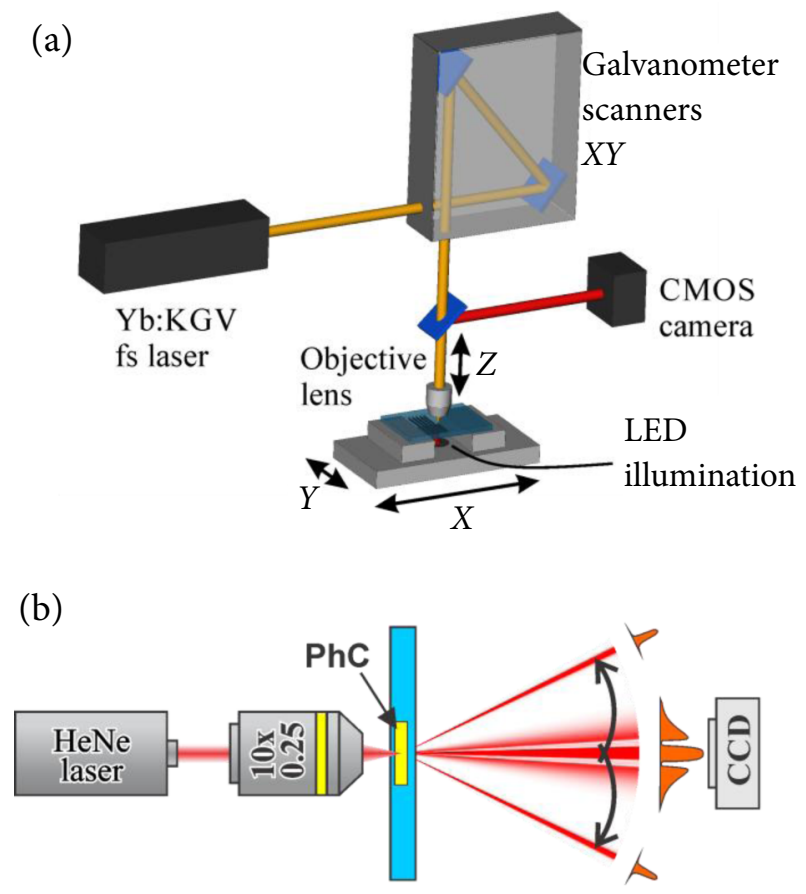

Fig. 3. Illustration of $\mathrm{PhC}$ fabrication (a) and characterization setup (b).

Calibration was performed while measuring the saturation value $N_{\max (s)}$ for which the filtering depth reaches the first peak as in Fig. 2(b).

For sample inspection, we additionally used an optical microscope. To perform the observations the glass samples were cut (using a manual glass cutter), optically polished perpendicularly to the inscribed lines with varied $d_{x}$ (variation in the range of 0.5 to $3 \mu \mathrm{m}$ ), and then examined under an optical microscope in the transmittance regime (Fig. 4). Smaller peak intensity values were used to produce the high contrast clearly observable line structures, since with higher levels of exposure the structures overlap more strongly, and change of spatial boundaries is even more difficult to observe. We chose the described inspection routine due to several reasons, such as a large size of a sample, the complexity of a structure and a small size of the modifications, which made the use of other possible inspection methods, such as microelipsometry [31] or refractive near-field techniques [32-33] not feasible.

\section{Results and discussion}

\subsection{Scattering efficiency measurement results}

The basic results are shown in Fig. 4, in which a crosssection view of extending modified areas is shown, and further summarized in Fig. 5. s-coefficient dependence on pulse energy has maxima for different frequencies of 


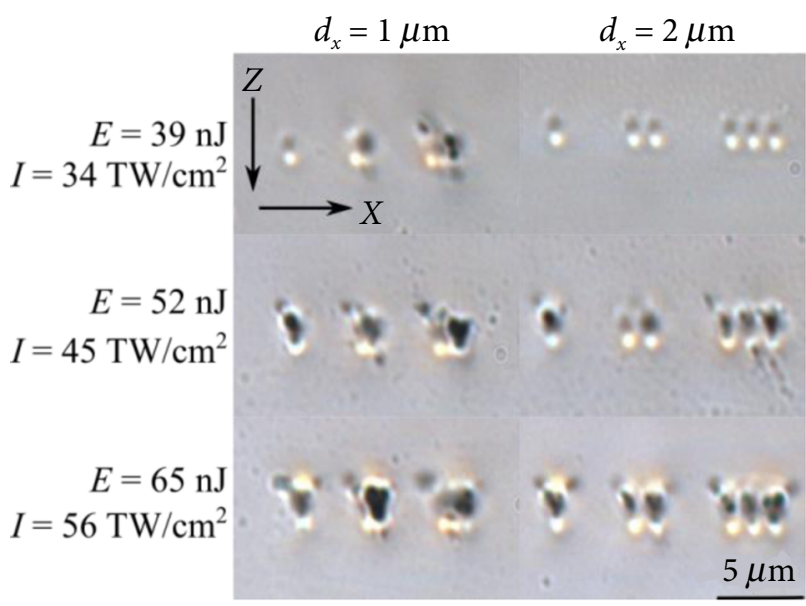

Fig. 4. Six examples of optical microscope cross-section views of mechanically cut and polished samples containing lines written in glass (with two different minimal distances between the closest neighbours). DLW order was chosen to be in the positive $x$ direction. Beam was incident in the $+z$ direction. The pulse repetition rate was $f=2 \mathrm{kHz}$.

writing pulses. Particularly, for $f=50 \mathrm{kHz}$ the highest value of $s$ was achieved with a pulse energy of $E=260 \mathrm{~nJ}$ and a peak intensity value of $I=224 \mathrm{TW} / \mathrm{cm}^{2}$.

The general trend in Fig. 5 allows claiming that the refractive index modulation depth of structures produced in glass is increasing with increasing pulse energy. However, not only the modulation depth increases with increasing pulse energy, but also the geometrical parameters change. We assume that when the size of index modified areas becomes too large (Fig. 4 shows that with increasing $E$ the modified refractive index structure increases in size), they start to overlap (clearly observed for the $d_{x}=1 \mu \mathrm{m}$ case), thus reducing the index modulation depth of the periodic structure and causing the decrease of the $s$-coeficient value for higher pulse energy/peak intensity values (Fig. 5).

By examining the single layer gratings, it was observed that the overlap of index modification areas occurs before reaching the critical pulse energy (resulting in the highest $s$, Fig. 5). This might seem like a counterintuitive result, but for parameters, such as used in our experiment, soda-lime rarefaction (decrease of density) occurs at the centre of the femtosecond pulse absorbing area and densifications at the boundaries, and when densified areas from two linear modifications overlap, then the largest modulation depth is achieved. If we take into consideration Eq. (1) and assume a continuous refractive index modulation pattern (see Appendix $\mathrm{B}$ ), then the maximum local depth would be $\Delta n_{\max } \approx 2 \cdot 10^{-3}$, which is a smaller value than that estimated in [16].
It should be noted that this overlap mechanism is not always clearly observed for different gratings at various writing conditions, as seen from Fig. 4 . For low modulation depths (low values of $s<0.025$ ) the modifications can be optically observed (e. g. $E=39 \mathrm{~nJ}$ ), but no sufficiently functional PhCs can be produced. Therefore, a high optically observable contrast is not indicative of the observable filter performance.

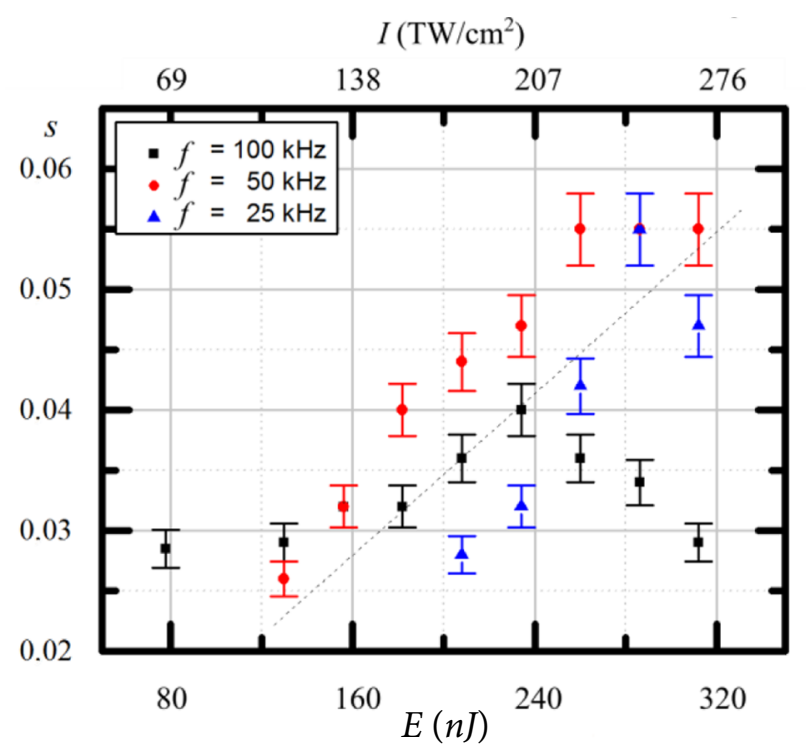

Fig. 5. Illustration of selected results. A summary of averaged $s$ measurements as dependent on frequency and pulse energy. Dotted line shows a general trend of $s$ increase until an observed peak or saturation $(s \lesssim 0.06)$ is reached. Lower energy values for which $s$ could not be measured $(s<0.025)$ are omitted.

\subsection{Asymmetric voxels}

Weakly asymmetric filtering spatial spectra patterns were observed in the cases of Fig. 5, especially when deviating from $E_{\max (s)}$ and $I_{\max (s)}$ values. Such behaviour was unexpected, and we chose to further explore the influence of the DLW beam polarization angle and beam writing direction to isolate possible unusual interaction mechanisms. After choosing different fabrication parameters and geometries containing different values of $d_{x}$, we found cases where the effect is pronounced. A selection of particular cases is shown in Fig. 6 .

For the cases with $d_{x}=1.2 \mu \mathrm{m}$, where a strong transverse voxel overlap occurs, the dominant filtering lines change from one diffraction minimum to another. For another instance where $d_{x}=1.4 \mu \mathrm{m}$, the asymmetry appeared without any change, depending on different values of $\gamma$. Asymmetry that is explained by 


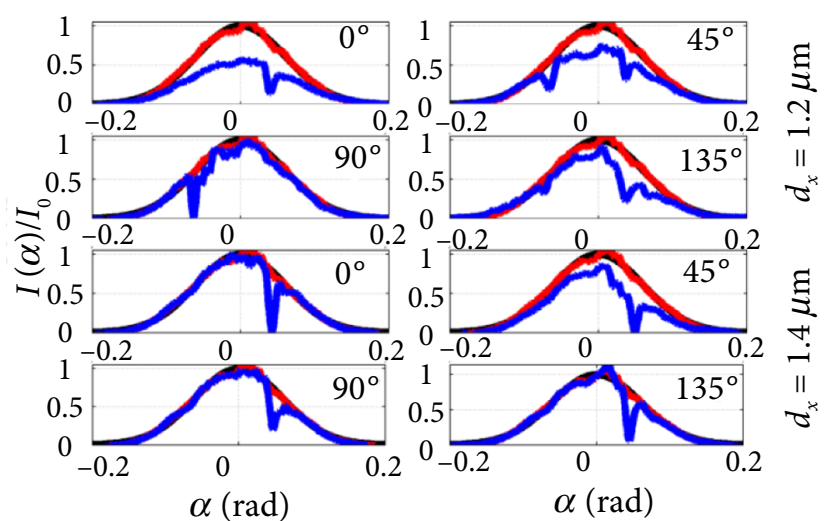

Fig. 6. Filtering patterns for different geometries and DLW beam polarization.

the far-field component diffraction from $+k_{x}$ to $+k_{x}+q_{x}$ becomes more efficient (less efficient for $-k_{x}$ to $-k_{x}-q_{x}$ ). This implies that in order to describe the PhC filter not one but two scattering coefficient values are needed: $s_{+q} \neq s_{-q}$ and also the refractive index modified structure is itself asymmetrical, the asymmetry depends on both the polarization and the relative scanning direction of the DLW beam.

The modified refractive index areas most probably contain an effectively tilted structure. To check the viability of such assumption, we performed numerical calculations to simulate PhCs having a harmonic type volume grating structure with different angles of a tilt. The tilted structures and resulting beam angular spectra are shown in Fig. ․ No asymmetry is observed when voxels have a zero tilt (Fig. Ұ(a)), yet the asymmetry starts to appear with a homogeneously increased tilt angle as seen in Fig. $7(b-c)$.

We expected a semi-homogeneous tilt structure, where the unidirectional raster scan was employed, but it was not always observed (e. g. the case in Fig. 6: $d_{x}=1.2 \mu \mathrm{m}, \gamma=45^{\circ}$ ). Also, a strong asymmetry was not always observed in the filtering patterns for the parameter sets of Fig. 5, but a possible explanation is found in Fig. F(d). As the tilt direction is reversed for each individual $\mathrm{PhC}$ plain, structures of different tilt might compensate the effect. In reality, the refractive index profile might be even more complex, as can be seen from Fig. 4, where Y-shaped cracks form along the length of the $\mathrm{PhC}$.

\section{Conclusions}

In this article, we presented a study of PhC spatial filters characterizing $s$-coefficient dependence of laser direct writing conditions in soda-lime glass.

We have found that for different pulse repetition rates $s$ increases together with the irradiation intensity peak value until it reaches a peak or saturation value.
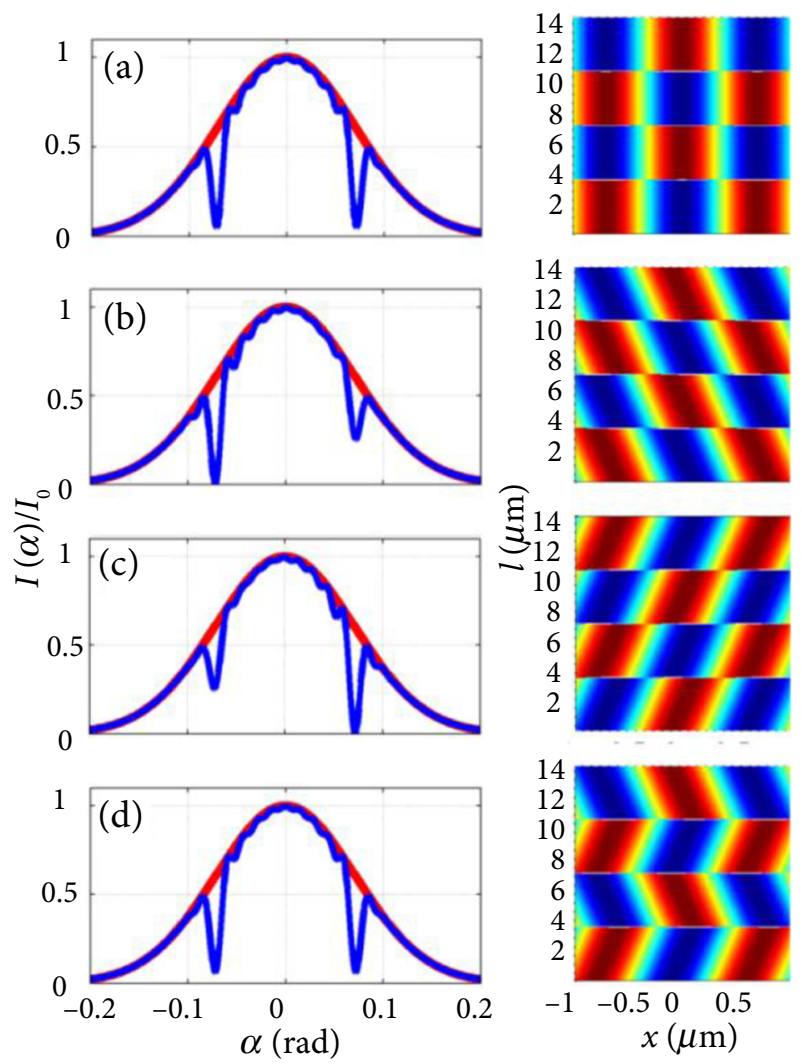

Fig. 7. Results of numerical simulations (see Appendix C). Different angular spectra (blue online) result for an input Gaussian beam (red online) for a $15 \mathrm{deg}$. tilt harmonic modulation structure model. (a) is the regular structure, (b) and (c) are opposite homogeneously tilted structures, (d) is the alternating tilt structure.

We have formulated a possible explanation, where for different fabrication conditions the redistribution of material density between successive linear writing operations plays a detrimental role in achieving the highest $s$-coefficient available. Under optimal writing conditions rarefaction at the centre of irradiation and densification around the rarefied centres can be beneficial in the formation of harmonic modulation of the PhCs layers, which is not seen in a conventional measurement due to increased diffraction.

Also, we have shown that scattering from different intended filtering lines in the $\mathrm{PhC}$ transmittance spectrum can become asymmetrical for different DLW polarizations and scanning patterns. Therefore, the behaviour of $\mathrm{PhC}$ filters cannot always be described in using a single value $s$, but needs to be characterized in terms of separate values, for example, $s_{+q^{\prime}} s_{-q}$. As a result, writing a $2 \mathrm{D}$ filter with maximal symmetry requires that PhC geometry factors, the DLW direction and beam polarization should be taken into account as well.

However, little is known about the distribution of the refractive index inside the processed glass that would 
help to further improve the technology and understanding of real PhCs. In light of this, more research is needed to improve the models and also the fabrication procedures for determining the best DLW conditions.

\section{Acknowledgements}

We acknowledge financial support by FOKER (No. MIP-14459) from the Research Council of Lithuania, and by Spanish Ministerio de Educación y Ciencia and European FEDER (Project No. FIS201129734-C02-01).

\section{Appendix A: Mathematical model}

Here we derive the scalar wave equation for the propagation of the unipolarized electric field E. For simplicity's sake the $\mathbf{E}$ is polarized along the "bars" of the $\mathrm{PhC}$ layer ( $y$ direction - TM polarization). The refractive index is expected to be in the form of

$$
n(x, z) \triangleq n_{0}+\Delta n(x, z)
$$

where $n(x, z)$ is the local value of the refractive index, $n_{0}$ is the average ambient refractive index, and $\Delta n(x, z)$ is the local deviation from $n_{0}$, expected to be $\Delta n(x, z) \ll n_{0}$.

For a complex wave function describing the electric field $\mathbf{E}(x, z, t)=\mathbf{E}(x, z) \mathrm{e}^{\mathrm{i} \omega t}$, with a complex amplitude $E(x, z)=A(x, z) \mathrm{e}^{\mathrm{i} \varphi(x, z)}$ and a complex envelope $A(x, z)$, the wave equation can be written down as

$$
\nabla^{2} \mathbf{E}(x, z, t)-\frac{1}{c^{2}(x, z)} \frac{\partial^{2} \mathbf{E}(x, z, t)}{\partial t^{2}}=0
$$

with $\nabla^{2}=\partial^{2} / \partial x^{2}+\partial^{2} / \partial z^{2} . c(x, z)$ is the local speed of light expressed as $c(x, z)=c_{0} / n(x, z)$ and using $k_{0} \triangleq \omega / c_{0}$ and the approximation $\left(n_{0}+\Delta n(x, z)\right)^{2} \approx n_{0}{ }^{2}+2 \Delta n(x$ , $z) n_{0}$, together with the slowly varying envelope approximation $\partial A(x, z) / \partial z \ll A(x, z) z$, we arrive at

$$
\frac{\partial A(x, z)}{\partial z}=\frac{\mathrm{i}}{2 k} \frac{\partial^{2} A(x, z)}{\partial x^{2}}+\mathrm{i} k \frac{\Delta n(x, z)}{n_{0}} A(x, z) .
$$

This equation is correct as long as two conditions are satisfied. First, the refractive index modulation $\Delta n(x, z)$ must be small compared to the average refractive index $n_{0}$, which in the case of this paper is lower than $\Delta n<10^{-2}$. Second, $\mathrm{PhC}$ periods must be larger than the wavelength. In our case, where interlayer distances are on the average $d_{\mathrm{z}}=3 \mu \mathrm{m}$ and larger, the relation is $n_{0} d_{z} / \lambda \leq 7.2$, which is sufficient.

\section{Appendix B: Scattering by one layer}

Here we want to relate the $s$, that is the amplitude scattering coefficient from one layer (grating) of a $\mathrm{PhC}$, to the maximum modulation of the refraction index $\Delta n_{\text {max }}$. If the plane wave $A\left(x ; z_{0}\right)=A_{0}$ illuminates the grating with the wavenumber $q=2 \pi / d_{x}\left(d_{x}\right.$ is the transverse period), then the field behind the grating becomes

$$
A\left(x, \Delta z=2 l_{0}\right)=A_{0}\left(1+\mathrm{i} s\left(\mathrm{e}^{\mathrm{i} q x}+\mathrm{e}^{-\mathrm{i} q x}\right)\right) .
$$

This is valid for weakly scattering gratings $s \ll 1$, in the linear approximation with respect to $s$. (In the next quadratic approximation with respect to $s$ the transmitted wave will be $A\left(x, \Delta z=2 l_{0}\right)=A_{0}\left(1-s^{2}+\mathrm{i} s\left(\mathrm{e}^{\mathrm{i} q x}+\mathrm{e}^{-\mathrm{i} q x}\right)\right)$, fulfilling the energy conservation, however, for simple estimation the linear approximation is sufficient). We assume that a refractive index modulation profile follows a cosine along the transversal and Gaussian function in the longitudinal direction:

$$
\Delta n(x, z) \stackrel{\Delta}{=} \Delta n_{\text {max }} \cos (q x) \mathrm{e}^{-z^{2} / l_{0}^{2}},
$$

where $l_{0}$ is the thickness of one layer.

If we ignore the diffraction term in (A3) and perform integration of (B2), we arrive at a solution in the form of

$$
\frac{A(x, z)}{A_{0}}=\exp \left(\frac{\mathrm{i} \pi \Delta n_{\max }\left(\mathrm{e}^{\mathrm{i} q x}+\mathrm{e}^{-\mathrm{i} q x}\right)}{\lambda_{0}} \int_{z_{0}}^{z} \mathrm{e}^{-\frac{z^{2}}{l_{0}^{2}}}\right) .
$$

Assuming the layer thickness is less than the interlayer distance $d_{\mathrm{z}} \geq 2 l_{0}$, the Taylor series expansion of the exponent up to the first term and integration yields

$$
\begin{aligned}
& A\left(x, \Delta z=2 l_{0}\right) \approx \\
& A_{0}\left(1+\mathrm{i} \frac{\pi^{3 / 2} l_{0} \Delta n_{\max }}{\lambda_{0}} \mathrm{e}^{\mathrm{i} q x}+\frac{\pi^{3 / 2} l_{0} \Delta n_{\max }}{\lambda_{0}} \mathrm{e}^{-\mathrm{i} q x}\right) .
\end{aligned}
$$

Comparing (B4) to (B1) shows that $s$ can be expressed as (1). In this way we have estimated the amplitude scattering coefficient $s$ for symmetric phase gratings, where the wave is equally directed to the $+q$ and $-q$ components. For asymmetric gratings considered in the main part of the article the amplitude scattering coefficients are $s_{+q} \neq s_{-q}$, respectively.

\section{Appendix C: Numerical method}

To calculate the complete angular spectra for regular $\mathrm{PhC}$ and asymmetrical $\mathrm{PhC}$ structures we used a splitstep method approach (a detailed implementation for the general case is found in [34]). The split-step method is used when diffractive homogenous space propagation can be evaluated separately from scattering from an infinitely thin phase grating, which, in this case, applies to one crystal layer, where the feature spatial period size is larger than the wavelength $d_{x^{\prime}}, d_{z}>\lambda$. 
A scattering operator (matrix) is defined as $\mathbf{S}_{\mathrm{j}}=\exp \left(\mathrm{i}^{2} \boldsymbol{s} \mathbf{M}_{\mathrm{j}}\right)\left(\mathbf{M}_{\mathrm{j}}\right.$ can be defined as $(-1)^{\mathrm{i}} \cos (q x)$, with $j=1,2 \ldots N$ counting the $\mathrm{PhC}$ layers), together with a propagation operator $\mathbf{P}=\exp \left(\mathrm{i} \frac{d_{z}}{2} \sqrt{k_{0}^{2}-k_{x}^{2}}\right)$. The resulting $\mathbf{A}_{0} \rightarrow \mathbf{A}_{N}$ field for a $\mathrm{PhC}$ having $N$ layers can be calculated by iteratively performing this operation:

$$
\mathbf{A}_{\mathrm{j}}=F^{-1}\left(\mathbf{P} F\left(\mathbf{S A}_{\mathrm{j}-1}\right)\right) \text {. }
$$

$F$ and $F^{-1}$ are the discrete Fourier and inverse Fourier transform operators.

If the structure is irregular, $(\mathrm{C} 1)$ has to be modified to be applied not $N$ times, but $m \cdot N$. In this case, $m$ is the sublayer step number for a sublayer of thickness $d_{z} / m . \mathbf{S}_{j, p}$ and $\mathbf{M}_{j, p}$ become dependent on an additional iteration number $p=1,2, \ldots \mathrm{m}$. A new parameter $\theta_{p}$ is introduced: $\mathbf{M}_{j, p}=(-1)^{j} \cos \left(q x+p \theta_{p} d / m\right)$ to control the new phase term that is responsible for displacing the phase grating along the $x$ direction for every sublayer step $m$ in the $z$ direction. The scattering coefficient must also be scaled $s \rightarrow s / m$ to avoid incorrect modeling $m$ times more efficient PhCs. In the simplest case $\theta_{p}=$ const, and selected according to the desired tilt value.

\section{References}

[1] A.E. Siegman, Defining, measuring, and optimizing laser beam quality, Proc. SPIE 1868, 2-12 (1993), http://dx.doi.org/10.1117/12.150601

[2] J.I. Kato, I. Yamaguchi, and H. Tanaka, Nonlinear spatial filtering with a dye-doped liquid-crystal cell, Opt. Lett. 21, 767 (1996), http://dx.doi.org/10.1364 OL.21.000767

[3] I. Moreno, J.J. Araiza, and M. Avendano-Alejo, Thin-film spatial filters, Opt. Lett. 30, 914 (2005), http://dx.doi.org/10.1364/OL.30.000914

[4] D. Shurig and D.R. Smith, Spatial filtering using media with indefinite permittivity and permeability tensors, Appl. Phys. Lett. 82, 2215 (2003), http:// dx.doi.org/10.1063/1.1562344

[5] O.F. Siddiqui and G. Eleftheriades, Resonant modes in continuous metallic grids over ground and related spatial-filtering applications, J. Appl. Phys. 99, 083102 (2006), http://dx.doi.org/10.1063/1.2189929

[6] A. Žukauskas, M. Malinauskas, and E. Brasselet, Monolithic generators of pseudo-nondiffracting optical vortex beams at the microscale, Appl. Phys. Lett. 103, 181122 (2013), http://dx.doi. org/10.1063/1.4828662

[7] E. Colak, A.O. Cakmak, A.E. Serebryannikov, and E. Ozbay, Spatial filtering using dielectric photonic crystals at beam-type excitation, I. Appl. Phys. 108, 113106 (2010), http://dx.doi. org/10.1063/1.3498810
[8] A.Y. Petrov and E. Ozbay, Toward photonic crystal based spatial filters with wide angle ranges of total transmission, Appl. Phys. Lett. 94, 181101 (2009), http://dx.doi.org/10.1063/1.3127443

[9] Z. Luo, Z. Tang, Y. Xiang, H. Luo, and S. Wen, Polarization-independent low-pass spatial filters based on one-dimensional photonic crystals containing negative-index materials, Appl. Phys. Lett. B 94, 641-646 (2009), http://dx.doi.org/10.1007/ s00340-009-3376-4

[10]Z. Tang, D. Fan, S. Wen, Y. Ye, and C. Zhao, Lowpass spatial filtering using a two-dimensional selfcollimating photonic crystal, Chin. Opt. Lett. 5(S1), 211-213-3 (2007).

[11]E. Yablonovitch, Inhibited spontaneous emission in solid-state physics and electronics, Phys. Rev. Lett. 58, 2059-2062 (1987), http://dx.doi.org/10.1103/ PhysRevLett.58.2059

[12]R. Picó, V.J. Sánchez-Morcillo, I. Pérez-Arjona, and K. Staliunas, Spatial filtering of sound beams by sonic crystals, Appl. Acoust. 73, 302-306 (2012), http://dx.doi.org/10.1016/j.apacoust.2011.09.011

[13] R. Picó, I. Pérez-Arjona, V.J. Sánchez-Morcillo, and K. Staliunas, Evidences of spatial (angular) filtering of sound beams by sonic crystals, Appl. Acoust. 74, 945-948 (2013), http://dx.doi. org/10.1016/j.apacoust.2013.01.003

[14]K. Staliunas and V.J. Sánchez-Morcillo, Spatial filtering of light by chirped photonic crystals, Phys. Rev. A 79(5), 053807 (2009), http://dx.doi.org/10.1103/ PhysRevA.79.053807

[15]L. Maigyte, T. Gertus, M. Peckus, J. Trull,C.Cojocaru, V. Sirutkaitis, and K. Staliunas, Signatures of lightbeam spatial filtering in a three-dimensional photonic crystal, Phys. Rev. A 82(4), 043819 (2010), http://dx.doi.org/10.1103/PhysRevA.82.043819

[16] V. Purlys, L. Maigyte, D. Gailevicius, M. Peckus, M. Malinauskas, and K. Staliunas, Spatial filtering by chirped photonic crystals, Phys. Rev. A 87, 033805 (2013), http://dx.doi.org/10.1103/ PhysRevA.87.033805

[17] V. Purlys, L. Maigyte, D. Gailevicius, M. Peckus, M. Malinauskas, R. Gadonas, and K. Staliunas, Spatial filtering by axisymmetric photonic microstructures, Opt. Lett. 39(4), 929-932 (2014), http://dx.doi.org/10.1364/OL.39.000929

[18]D. Gailevicius, V. Purlys, L. Maigyte, M. Peckus, and K. Staliunas, Chirped axisymmetric photonic microstructures for spatial filtering, J. Nanophoton. 8(1), 084094 (2014), http://dx.doi.org/10.1117/1. INP.8.084094

[19]K. Staliunas, Removal of excitations of BoseEinstein condensates by space- and time-modulated potentials, Phys. Rev. A 84, 013626 (2011), http://dx.doi.org/10.1103/PhysRevA.84.013626

[20]A. Zukauskas, G. Batavičiūtè, M. Sčiuka, T. Jukna, A. Melninkaitis, and M. Malinauskas, Characterization of photopolymers used in laser 3D micro/ 
nanolithography by means of laser-induced damage threshold (LIDT), Opt. Mater. 4(8), 1601-1616 (2014), http://dx.doi.org/10.1364/OME.4.001601

[21] J. Fischer and M. Wegener, Three-dimensional optical laser lithography beyond the diffraction limit, Laser Photonics Rev. 7(1), 22-44 (2013), http:// dx.doi.org/10.1002/lpor.201100046

[22]V. Purlys, L. Maigyte, D. Gailevicius, M. Peckus, R. Gadonas, and K. Staliunas, Super-collimation by axisymmetric photonic crystals, Appl. Phys. Lett. 104, 221108 (2014), http://dx.doi.org/10.1063/1.4881839

[23]L. Maigyte, V. Purlys, J. Trull, M. Peckus, C. Cojocaru, D. Gailevicius, M. Malinauskas, and K. Staliunas, Flat lensing in visible frequency range by woodpile photonic crystals, Opt. Lett. 38(14), 2376-2378 (2013), http://dx.doi.org/10.1364/OL.38.002376

[24] L. Maigyte and K. Staliunas, Spatial filtering with photonic crystals, App. Phys. Rev. 2, 011102 (2015), http://dx.doi.org/10.1063/1.4907345

[25]C. Malouin, A. Villeneuve, G. Vitrant, and R.A. Lessard, Degenerate four-wave mixing geometry in thinfilm waveguides for nonlinear material characterization, Opt. Lett. 21(1), 21-23 (1996), http://dx.doi. org/10.1364/OL.21.000021

[26] S. Nolte, M. Will, J. Burghoff, and A. Tuennermann, Femtosecond waveguide writing: a new avenue to three-dimensional integrated optics, Appl. Phys. A 77(1), 109-111 (2003).

[27]H. Zhang, S.M. Eaton, and P.R. Herman, Singlestep writing of Bragg grating waveguides in fused silica with an externally modulated femtosecond fiber laser, Opt. Lett. 32(17), 2559 (2007), http:// dx.doi.org/10.1364/OL.32.002559

[28] M. Beresna, M. Gecevičius, P.G. Kazansky, and T. Gertus, Radially polarized optical vortex converter created by femtosecond laser nanostructuring of glass, Appl. Phys. Lett. 98, 201101 (2011), http://dx.doi.org/10.1063/1.3590716

[29] M. Malinauskas, P. Danilevičius, and S. Juodkazis, Three-dimensional micro-/nano-structuring via direct write polymerization with picosecond laser pulses, Opt. Express 19, 5602 (2011), http://dx.doi. org/ 10.1364/OE.19.005602

[30]S. Nisara, M.A. Sheikha, L. Lia, and S. Safdarb, Effect of thermal stresses on chip-free diode laser cutting of glass, Opt. Laser. Technol. 41(3), 318-327 (2009), http://dx.doi.org/10.1016/j.optlastec.2008.05.025

[31] K.M. Davis, K. Miura, N. Sugimoto, and K. Hirao, Writing waveguides in glass with a femtosecond laser, Opt. Lett. 21(21), 1729-1731 (1996), http:// dx.doi.org/10.1364/OL.21.001729

[32] A.M. Streltsov and N.F. Borrelli, Fabrication and analysis of a directional coupler written in glass by nanojoule femtosecond laser pulses, Opt. Lett. 26(1), 42-43 (2001), http://dx.doi.org/10.1364/ OL.26.000042

[33] A.M. Streltsov and N.F. Borrelli, Study of femtosecond-laser-written waveguides in glasses, J. Opt. Soc. Am. B 19(10), 2496-2504 (2002), http:// dx.doi.org/10.1364/JOSAB.19.002496

[34] T.-C. Poon and T. Kim, Engineering Optics with Matlab (World Scientific, Singapore, 2006).

\title{
ERDVINIŲ FILTRŲ TIESIOGINIS LAZERINIS FORMAVIMAS FEMTOSEKUNDINIAIS IMPULSAIS NATRIO-KALCIO SILIKATINIAME STIKLE
}

\author{
D. Gailevičius ${ }^{\text {a }}$, V. Purlys ${ }^{\text {a }}$, L. Maigyte ${ }^{\text {b }}$, E. Gaižauskas ${ }^{\text {a }}$, M. Peckus ${ }^{\text {a }}$, R. Gadonas ${ }^{\text {a }}$, K. Staliūnas ${ }^{\text {b,c }}$ \\ ${ }^{a}$ Vilniaus universiteto Lazeriniu tyrimu centras, Vilnius, Lietuva \\ ${ }^{\mathrm{b}}$ Katalonijos politechnikos universiteto Fizikos ir branduolinés inžinerijos katedra, Terasa, Ispanija \\ ${ }^{c}$ Katalonų tyrimų ir aukštujų studijų institutas, Barselona, Ispanija
}

\section{Santrauka}

Erdvinis filtravimas dažnai naudojamas lazerinių pluoštų erdvinei kokybei gerinti. Neseniai buvo parodytas erdvinis pluoštų filtravimas fotoniniais kristalais (FK) [24]. Šiame darbe tiriama šių naujo tipo FK erdvinių filtrų efektyvumo priklausomybè nuo FK įrašymo sąlygų. Fotoniniai dariniai suformuoti tiesioginio lazerinio rašymo būdu taikant pataškini medžiagos lūžio rodiklio modifikavimą aštriai sufokusuotais femtosekundiniais impulsais natrio-kalcio silikatiniame stikle. Tokie FK yra apibūdinami panaudojus s-koeficientą - parametrą, skirtą apibrèžti FK filtro efektyvumą. Nagrinèjama filtravimo efektyvumo priklausomybė nuo skirtingu lazerinio įrašymo sąlygų, pavyzdžiui, smailinio spinduliuotès intensyvumo ir lazerio pluošto poliarizacijos. $\mathrm{Pa}$ rodoma, kad esant atitinkamoms įrašymo sąlygoms FK gali pasižymèti asimetriška vokselių sandara. 